\title{
MERCOSUR: its challenges to small and medium-sized industrial enterprises in terms of competition
}

\section{Francisco Gatto}

ECLAC

Buenos Aires Office.
This article seeks to contribute some elements and considerations that may help to understand the challenges faced by small and medium-sized enterprises (SMEs) in terms of competition as the integration process in MERCOSUR is consolidated. Although many of the views expressed here are applicable to the small and medium-sized enterprises of the MERCOSUR countries in general, this study deals in particular with the situation of the Argentine and Uruguayan SMEs. It begins by summarizing some basic data on SMEs in MERCOSUR (section II). It tries to identify the main challenges that these enterprises must cope with (from the entrepreneurial standpoint) if they are to take advantage of the integration process to further the growth of their business activities and the international expansion of their firms (section III). It reviews some basic common features of industrial SMEs, some of which are central elements in determining the transformation of enterprises faced with the challenges in question (section IV), and finally it makes some brief comments on support systems in this new state of affairs. The needs of the SMEs may be grouped in four areas: i) improvement of the regulatory and operational framework for their business activities; ii) access to specific information and advisory assistance for its interpretation (trade information, technical standards and technological consultancy services); iii) the formation of in-house capabilities (human resources, especially in the areas of entrepreneurial and management skills) and easier access to the technical services infrastructure, and iv) access to finance on terms which really are comparable with those of larger firms, which in some cases involves the implementation of new financial instruments and products. The strategic challenge of industrial policy for SMEs is to create and promote a climate of positive change. Public policy cannot define or bring about such change in firms, as it was once believed in a voluntaristic and omnipotent manner. Instead, public policy must stimulate and create the best possible conditions for ensuring that this change takes place efficiently, favouring the establishment of lasting collective synergies. Otherwise, public policy would be guilty of taking a passive stance (not doing anything) or actually holding back progress (by encouraging actions in the opposite direction). 


\section{I}

\section{Introduction}

This study seeks to promote a better awareness of the competitive challenges faced by small and medium-sized enterprises (SMEs) as the MERCOSUR integration process advances. Although many of the ideas set forth here apply to the SMEs of the MERCOSUR countries in general, we will be referring in particular to the situation of Argentine and Uruguayan small and medium-sized enterprises. ${ }^{1}$

The economic and productive activities of the industrial SMEs since the early 1990s have taken place in the midst of a process of great macroeconomic and regulatory changes. These changes at the national level have also been accompanied by changes in the international economic, trade and technological context. The MERCOSUR integration process is one of the new factors conditioning the regional economic scene, and although it is not the factor which has most seriously affected firms during the early 1990s, it is having structural repercussions on the conduct of firms in terms of production, on the definition of their future business strategies, and on their investment decisions. Thus, MERCOSUR has gradually ceased to be seen only as a factor of greater competitive pressures and has begun to be considered as a broad range of new trade opportunities and production options (business complementation agreements, subcontracting possibilities, business mergers, extension through licenses).

The central hypothesis of this article is as follows: for a great many of the SMEs -especially for

This article is based on a paper presented at the sectoral conference on strategies to promote the economy and employment in MERCOSUR, organized by the GTZ in Asunción in September 1997 (1st revision, February 1998; 2nd revision, November 1998).

${ }^{1}$ As will be noted from section II, Brazilian enterprises account for almost $80 \%$ of all industrial SMEs in MERCOSUR: Brazil is also by far the biggest national market in MERCOSUR (several times the size of the rest of the member countries) thus creating a very uneven situation as regards such enterprises as a whole: for many of them -i.e., the Brazilian enterprises- the MERCOSUR market is largely the same as their own previous domestic market. For the rest of the member countries, in contrast, the potential market created by the integration process may represent over ten times their previous domestic market. those in Argentina and Uruguay which produce tradeable manufactures for which demand is differentiated, segmented and subject to the influence of international technological and consumption patterns, or for producers of intermediate goods, parts or components for use by assembly or terminal industries - the present stage could be described as one of "redesigning business", that is to say, re-founding or rethinking production activity and business strategies. This is because the conditions in which these enterprises were set up and managed by their owners in the past have undergone substantial changes and because the firms need to re-insert themselves into a new productive, technological, trade and business situation which is not only much more internationalized but is also beginning to organize itself on the basis of an expanded market with special treatment.

Although the SMEs had already been adapting themselves to the economic and market conditions facing them, the changes in the macroeconomic, regulatory and technological context -including of course the MERCOSUR integration process- have now placed them in a completely different situation which affects the very roots of the firms, their objectives, their way of operating and taking decisions, their competitive advantages, and the capabilities and resources required, among other things. The present challenges to manufacturing SMEs are not those typical of a mere transitory adjustment (such as is required by a trade recession) but are challenges calling for change and innovation which define a new starting point with all the future consequences deriving from it. The fact that there is practically no question of a return to the previous situation without incurring very high costs, because of the decisions and investments already made, is reflected in the great concern over the appearance of trade disputes, disagreements over customs procedures and macroeconomic uncertainty among entrepreneurs who have made successful progress in MERCOSUR and have gradually adopted it as the environment for their business activities and competition. This change will mean altering traditional forms of behaviour and operation which are deeply rooted in firms and setting 
afoot a deliberate process of construction of new competitive capabilities which must be based on the know-how and learning (intangible assets) available in the firm and access to technical support systems and must be accredited in the new conditions and dynamics of demand and markets.

\section{II}

\section{Industrial SMEs in MERCOSUR. Some basic details}

In view of the different definitions of SMEs used in each country (table 1) and the absence of updated and compatible statistical information, it is very difficult to make an estimate of the number of industrial firms of this type in MERCOSUR, of the size and evolution of employment in them, and of their share in manufacturing output and industrial exports (Gatto and Ferraro, 1993). In this article, we will consider manufacturing SMEs to be manufacturing enterprises employing between 5 and 150 workers, thus excluding micro-enterprises and informal and clandestine urban activities. In view of the big differences between the production structures of the different countries, an industrial enterprise with 50 workers, for example, could be considered to be large in a country with a small economy and might even account for a significant share of the respective sector of the domestic market, whereas in another country it might be just another economic agent and not occupy a leading position.

According to available partial information, a reasonable estimate for the mid 1990s would indicate that the total universe of industrial SMEs in MERCOSUR (defined as independent enterprises with between 5 and 150 employees) comprised between 120000 and 130000 manufacturing enterprises generating some 2700000 direct jobs; it may be assumed that around $80 \%$ of these enterprises were located in Brazil and around 15-17\% in Argentina. ${ }^{2}$

\footnotetext{
2 According to the 1994 National Economic Census, in that year there were 25000 enterprises with between 6 and 150 workers in Argentina, out of a total of 90088 industrial production units (INDEC, 1997). In 1985, which is the year of the last available census for Brazil, industrial establishments of this size numbered around 90000 out of a total of almost 180000 production units registered. This figure had very likely risen to around 100000 by the mid-1990s.
}

Out of this universe, rather more than half are in sectors that manufacture tradeable goods at the regional (MERCOSUR) and international level. The rest are engaged in satisfying the local demand for non-durable consumer goods. In other words, some $60 \%$ of the SMEs located in MERCOSUR are exposed to the consequences of the integration process, both through the opening of new trade and production opportunities and through the increased threat and competitive pressures from companies in other countries. ${ }^{3}$ The degree to which they are positively or negatively affected varies greatly between different sectors and countries; obviously, the situation of an SME located in a country whose market grows by a factor of 10 or 15 thanks to MERCOSUR is not the same as that of a company located in Brazil, where the impact of MERCOSUR may be much smaller.

The industrial structure of small and medium-sized enterprises is concentrated on labour-intensive manufacturing activities, especially natural resources based industries (wood and furniture), agroindustries, agro-food industries and mature manufacturing activities (clothing and footwear, plastics, and metal products and machinery). SMEs in the food sector account for a larger share of the total in Uruguay than in the

\footnotetext{
3 According to the available statistical estimates, at the sub-sectoral level the Brazilian SMEs account for over $70 \%$ of total MERCOSUR production in all the manufacturing subsectors except food and beverages, hides and skins and textiles, where Argentina and Uruguay together account for over $30 \%$ of total production. In other words, the big difference between the size of Brazil and the other member countries means that at the level of the main industrial sectors there is no differentiated production specialization. At higher levels of sectoral and regional disaggregation, however, patterns of specialization of SMEs begin to emerge.
} 
Latin America: Definitions of microenterprises and small and medium-sized enterprises

\begin{tabular}{|c|c|c|c|c|}
\hline \multicolumn{5}{|c|}{ A. ARGENTINA } \\
\hline $\begin{array}{l}\text { Sectors (maximum } \\
\text { amount for sector) }\end{array}$ & $\begin{array}{c}\text { Number of persons } \\
\text { employed }\end{array}$ & $\begin{array}{l}\text { Annual sales } \\
\text { (millons of dollars) }\end{array}$ & $\begin{array}{l}\text { Productive assets } \\
\text { (millons of dollars) }\end{array}$ & Remarks \\
\hline $\begin{array}{l}\text { Industry, mining and } \\
\text { fisheries }\end{array}$ & 300 & 18.00 & 10.00 & $\begin{array}{c}\text { Formula maintained } \\
\text { unchanged from } \\
\text { the original }\end{array}$ \\
\hline Commerce and services & 100 & 12.00 & 2.50 & \\
\hline Transport & 300 & 15.00 & - & \\
\hline Agriculture $^{b}$ & - & 1.00 & 3.00 & \\
\hline
\end{tabular}

B. BRAZIL

\begin{tabular}{|c|c|c|c|c|}
\hline $\begin{array}{l}\text { Sectors (maximum } \\
\text { amount for sector) }\end{array}$ & $\begin{array}{c}\text { Number of persons } \\
\text { employed }\end{array}$ & $\begin{array}{l}\text { Net operating income } \\
\text { (millions of dollars) }\end{array}$ & \multicolumn{2}{|l|}{ Remarks } \\
\hline \multicolumn{3}{|l|}{ Industry } & \multirow{4}{*}{\multicolumn{2}{|c|}{$\begin{array}{l}\text { Criteria are alternative and are not } \\
\text { applied jointly }\end{array}$}} \\
\hline Microenterprises & Up to 19 & 0.13 & & \\
\hline Small-scale enterprises & 29 to 99 & 1.30 & & \\
\hline Medium-sized enterprises & 100 to 499 & 4.00 & & \\
\hline \multicolumn{5}{|l|}{ Commerce and services } \\
\hline Microenterprises & Up to 9 & 0.13 & & \\
\hline Small-scale enterprises & 10 to 49 & 1.30 & & \\
\hline Medium-sized enterprises & 50 to 99 & 4.00 & & \\
\hline \multicolumn{5}{|c|}{ C. URUGUAY } \\
\hline $\begin{array}{l}\text { All economic sectors } \\
\text { except financial inter- } \\
\text { mediation (maximum } \\
\text { amount for sector) }\end{array}$ & $\begin{array}{l}\text { Number of } \\
\text { persons } \\
\text { employed }\end{array}$ & $\begin{array}{l}\text { Maximum sales } \\
\text { (millions of } \\
\text { dollars) }\end{array}$ & $\begin{array}{l}\text { Maximun assets } \\
\text { (millions of } \\
\text { dollars) }\end{array}$ & Remarks \\
\hline Microenterprises & 1 to 4 & 0.06 & 0.02 & $\begin{array}{l}\text { The three limits must } \\
\text { all be fulfilled }\end{array}$ \\
\hline Small-scale enterprises & 5 to 19 & 0.18 & 0.05 & \\
\hline Medium-sized enterprises & 20 to 99 & 1.00 & 0.35 & \\
\hline \multicolumn{5}{|c|}{ D. MERCOSUR } \\
\hline $\begin{array}{l}\text { All economic sectors } \\
\text { (maximum amount for } \\
\text { sector) }\end{array}$ & $\begin{array}{l}\text { Number of persons } \\
\text { employed }\end{array}$ & $\begin{array}{c}\text { Sales } \\
\text { (millions of } \\
\text { dollars) }\end{array}$ & $\begin{array}{l}\text { Coefficient of } \\
\text { size }\end{array}$ & Remarks \\
\hline Microenterprises & Up to 20 & Up to 0.40 & Up to 0.52 & \multirow{3}{*}{$\begin{array}{l}\text { Number of points assigned } \\
\text { depends on a formula } \\
\text { (see note below) }\end{array}$} \\
\hline Small-scale enterprises & Up to 100 & Up to 2.00 & Up to 2.58 & \\
\hline Medium-sized enterprises & Up to 300 & Up to 10.00 & Up to 10.00 & \\
\hline
\end{tabular}

Source: Gatto and Ferraro (1993).

${ }^{\text {a }}$ Net of VAT and other domestic taxes.

${ }^{\mathrm{b}}$ For the agricultural sector, annual gross income is used instead of annual sales and productive capital instead of productive assets.

${ }^{\mathrm{c}}$ Aggregate amount used by the National Development Bank (BNDES) and the Banco do Brasil for financial assistance purposes.

${ }^{\mathrm{d}}$ Coefficient of size $=10 \sqrt{\frac{P O}{P O m} \frac{V}{V m}}$

where $P O=$ number of persons employed; $P O_{m}=$ reference number of persons employed; $V=$ annual sales of the enterprise; $V m=$ reference annual sales. The maximum values used are as follows: $P O_{m}=300$ persons; $V m=\mathrm{US} \$ 10$ billion. 
rest of the countries. ${ }^{4}$ In contrast, those engaged in manufacturing activities with a high technological content (defined as a function of the type of good produced rather than of the processes used) have a low share in the composition of production, since they account for less than 5-7\% of the total value of production of the SMEs. This percentage may even be lower, since in the allocation by census category it is not possible to distinguish exactly the type of process carried out in such enterprises (such as the final assembly of telecommunications equipment).

A significant part of the activities of SMEs are connected with the manufacture of intermediate products, parts, components, processes or sub-assemblies incorporated in other manufactured goods. The lack of updated statistical information prevents us from precisely quantifying the share of subcontractors or parts manufacturers, but there are indirect indications that their activities have grown considerably in recent years. Furthermore, they have been particularly affected by the process of external openness, since there has been an increase in imported intermediate inputs ${ }^{5}$ and in final products incorporating such intermediate goods.

This universe of small and medium-sized enterprises (with between 5 and 150 employees) is closely integrated into the industrial structure of each country, so that its level of efficiency, quality and productivity is a decisive factor in the competitiveness of

\footnotetext{
${ }^{4}$ The most important activities in the structure and composition of the industrial production of small and medium-sized enterprises are not manufacturing activities which are exclusive to the SMEs or where the latter have a majority share. The branches in which SMEs are particularly prominent (furniture, wood industries, plastics, and leather and furs) are not the most important in the industrial structure of small and medium-sized enterprises in MERCOSUR, and still less so in the manufacturing structure of MERCOSUR. In the industrial activities of SMEs in MERCOSUR, the four main manufacturing branches (foodstuffs, mechanical engineering and transport equipment, ready-made clothing and footwear, and metal products) account for less than $12 \%$ of total production and some $15 \%$ of employment, which indicates that these activities in which the SMEs are most active also have lower relative productivity within the universe of small and medium-sized enterprises.

${ }^{5} \mathrm{~A}$ complex consequence of the new foreign investment process within MERCOSUR is that many of the investments involve radical technological changes in the organization of production. The new plants not only have more modern equipment but have also been planned in line with new criteria on factory and production organization. This has a strong impact -not yet studiedon supplier SMEs, since they must relocate themselves within a scheme based on new operating criteria which inherently involve strong competitive pressures.
}

complex industrial sectors. ${ }^{6}$ Unlike what happens in the case of other economic agents (very small rural and urban producers), the production of industrial SMEs is not directed towards marginal activities or exclusively towards low-income market segments. Although some of these spaces have served as transitory refuges when SMEs have been displaced from their original markets, most enterprises operate in areas of production which are internationally linked by trade and technological innovation.

However, this situation has not yet had much effect on the particular and specific features of the MERCOSUR SMEs, which probably evolve more slowly and steadily. In other words, the process of macroeconomic change, external openness and integration has not necessarily or automatically led to a situation of growing entrepreneurial homogeneity, although the enterprises have pursued similar general objectives (such as improving quality or coming closer to the technical frontier reached by more advanced competitors).

As repeatedly noted in the international literature, SMEs are economic agents which are "genetically" different from larger companies, and they display differences which do not stem only from absolute size but also from features of their own nature and aspects of their functioning and economic management (Storey, 1987; Kantis, 1996; Walsh and White, 1981). At the same time, however, SMEs are integrated into the manufacturing production structure and are regulated by the global business environment, have direct (supply) and indirect (technological dissemination) relations with bigger firms, and compete in the market with domestic and foreign industrial or commercial firms of their own or larger size. In this sense, in order to properly interpret the impact of trade openness and MERCOSUR on the production sector made up of small and medium-sized enterprises it is necessary to analyse this impact in the global industrial context, including the dynamics of industrial chains or segments (such as the motor industry), the profile of new industrial investments, and the policies adopted with respect to their suppliers by

\footnotetext{
${ }^{6}$ Without arriving at the extremes of Japanese industry or of some Italian or German manufacturing subsectors, an important group of small and medium-sized suppliers can nevertheless make a significant contribution to the competitiveness and external linkages of other enterprises and sectors.
} 
TABLE 2

Argentina and Brazil: Mutual trade within MERCOSUR

\begin{tabular}{|c|c|c|c|c|c|c|}
\hline \multicolumn{4}{|c|}{ BRAZIL } & \multicolumn{3}{|c|}{ ARGENTINA } \\
\hline Year & $\begin{array}{c}\text { Total } \\
\text { imports }\end{array}$ & $\begin{array}{c}\text { Imports } \\
\text { from } \\
\text { Argentina }(\%)\end{array}$ & $\begin{array}{l}\text { Imports from } \\
\text { Argentina as \% } \\
\text { of total Argentine } \\
\text { exports }\end{array}$ & $\begin{array}{c}\text { Total } \\
\text { imports a }\end{array}$ & $\begin{array}{l}\text { Imports from } \\
\text { Brazil (\%) }\end{array}$ & $\begin{array}{l}\text { Imports from } \\
\text { Brazil as \% of } \\
\text { total Brazilian } \\
\text { exports }\end{array}$ \\
\hline 1986 & 15557.0 & 4.5 & 10.2 & 4724.2 & 14.6 & 3.1 \\
\hline 1987 & 16581.0 & 3.3 & 8.6 & 5817.8 & 14.1 & 3.1 \\
\hline 1988 & 16051.0 & 3.6 & 6.3 & 5321.1 & 18.3 & 2.9 \\
\hline 1989 & 20016.0 & 5.6 & 11.8 & 4199.9 & 17.2 & 2.1 \\
\hline 1990 & 22459.0 & 6.3 & 11.6 & 4077.4 & 17.6 & 2.3 \\
\hline 1991 & 21035.0 & 7.1 & 12.4 & 8275.0 & 18.4 & 4.8 \\
\hline 1992 & 20593.0 & 8.4 & 14.1 & 14872.0 & 22.4 & 9.2 \\
\hline 1993 & 25256.0 & 14.6 & 28.0 & 16784.0 & 21.1 & 9.2 \\
\hline 1994 & 32748.0 & 11.2 & 23.1 & 21518.2 & 20.1 & 9.9 \\
\hline 1995 & 49860.0 & 11.0 & 26.2 & 20123.0 & 20.7 & 9.0 \\
\hline 1996 & 53286.0 & 12.4 & 27.8 & 23810.3 & 22.4 & 11.2 \\
\hline 1997 & 61983.0 & 12.5 & 30.4 & 30419.7 & 22.7 & 13.0 \\
\hline
\end{tabular}

Source: ECLAC Office in Buenos Aires, on the basis of data from the National Institute of Statistics and Censuses (INDEC); ECLAC Office in Brasilia, and other sources.

${ }^{\text {a }}$ Millions of dollars of imports CIF.

leading firms in sectors making extensive use of components for assembly.

Finally, the ongoing consolidation of the MERCOSUR integration process is reflected very clearly in the external trade figures. The Argentine and Brazilian firms have managed to increase their shares in the imports of each country, which have grown at very rapid rates over the last ten years: $4 \%$ in the case of the imports of Brazil and 15\% in those of Argentina (table 2) in the last ten years. Thus, firms have managed to take advantage of the trade opportunities which have been opened up to them more rapidly (more so in the case of Argentina than in that of Brazil) than in other countries, thereby increasing their shares.

This overall picture, which is general for the large firms, is different in the SMEs sector. Although many of them have entered bilateral trade flows, more than doubling the number of small exporters, it has also been observed that there are many which have remained only in the domestic market, in a mainly defensive attitude.

\section{III}

\section{The main challenges as seen from the entrepreneurs' standpoint}

The impact of MERCOSUR on the SMEs is very varied and unequal, in keeping with the heterogeneity typical of this sector. This feature is not exclusive to SMEs in MERCOSUR but is also observed in industry and business in other countries (OECD, 1997). For this reason, the challenges described here largely reflect the concern of small and medium-sized entrepreneurs directly and appreciably affected by the integration process. For other SMEs (in sectors which do not produce many tradeable goods or are located in regions not affected by MERCOSUR) the entrepreneurial requirements are of a different nature.

In recent years, various studies (IDB, 1995; Ferraro, 1994) have been carried out on the competitive dynamics of SMEs, based on interviews with entrepreneurs and the preparation of specific infor- 
mation on the factors determining competitive advantages. These studies made it possible to identify the main medium-term business challenges and group them in four main blocks: i) restructuring the firm's "business" to fit in with the economic and production situation resulting from the MERCOSUR process; ii) repositioning the firm in terms of competitiveness with respect to the expanded market and beginning a process of internationalization; iii) updating technology to face the external competitive pressures of MERCOSUR, and iv) taking advantage of the new opportunities arising in MERCOSUR, especially those deriving from new investments.

\section{Restructuring the firm's "business" to fit in with the new economic and production situation}

From the point of view of the SMEs in Argentina, Uruguay and Paraguay (note that we are excluding those of Brazil, the largest country), the change in the size of the market and the increasingly close links between the sub-markets in each branch of manufacturing substantially alter not only the morphology of the markets and the optimum scales of production and operation but also the types of products offered, the levels of specialization of production, the supply of associated services, and other aspects. For most of the industrial SMEs, taking advantage of the growth in the market does not mean expanding proportionately but rather defining an expansion strategy on the basis of their effective capabilities, using parameters different from those employed to position themselves in their smaller national or sub-national markets. For many reasons, ranging from the availability of human resources in management to access to sources of finance, the SMEs follow a particular, non-linear growth path in which they must combine and balance the available areas of competence and capabilities -especially those of the owner and his closest management team- with the production and trade opportunities offered by the market. Many SMEs in the countries in question have opted for a specialized expansion strategy based on smaller product lines than those produced for the domestic market and a capacity to meet specific orders from clients (other firms or importers).

In this strategy, a particularly important aspect is the possibility of transferring to the new expanded market the competitive advantages on which the SMEs' production activities for the domestic market were based. The difficulties and limitations in extending those advantages to other contexts and markets (knowledge and information on their product or brand, reputation, flexibility in meeting orders, proximity to clients, direct relations with the market, etc.) mean that the firms must review not only aspects of factory organization but also other key elements in business activity, such as marketing, supply logistics and the ability to satisfy demand.

In a sense, this is one of the crucial items for the future expansion of such firms or even their survival as efficient enterprises. If we could make a table of the strengths and weaknesses of the industrial SMEs in their old domestic markets in comparison with the present MERCOSUR integration process, we would very probably note a certain contrast between their technical and productive strengths and their weaknesses in terms of management. SMEs mostly arose originally as a result of the technical competence of their owners, the tacit know-how and production skills of owners and workers, and skills connected with the manufacture of particular types of goods and the solution (within certain limits) of the technical problems posed by requirements of clients and the market. The firms were "governed" from the shop floor. Especially in recent decades, firms (i.e., their owners) began to learn to operate in situations of economic uncertainty, inflation and very short-term horizons. The response of the SMEs was aimed at strengthening their financial management and concentrating their management efforts on preventing the reigning instability and uncertainty from seriously affecting the economic life of the firm and its owners. In extreme cases, many firms (including small and medium-sized ones) managed to take advantage of the different economic situations and grew by exploiting the uncertain and volatile business climate.

The present situation, however, unlike the two kinds of situations referred to earlier, calls for other kinds of knowledge and competence, a new learning process, and the development of the capabilities needed for the new operating conditions.

External openness, together with the growing intra-MERCOSUR trade in everyday consumer goods (ready-made clothing, footwear, some types of plastic products), also changed the demand profile as a significant expansion took place in the options open 
to consumers as regards types of products (design, quality) and prices. The SMEs (especially those of Argentina and also to some extent those of Uruguay) faced a virtual shock situation in a number of these markets: because of the limited capacity and speed of response of local supply to the challenge of imports and the considerable magnitude of the latter, the possible ways of adapting to market changes went far beyond merely "matching" the final prices of the goods offered for sale: they involved investments, lead times and a technical learning process which was not always easy. In many cases, in order to make an active response it was necessary to introduce new products, with inputs, technical qualities and designs different from those normally used by local entrepreneurs; in other cases it was necessary to establish new distribution and marketing channels, different from those already used by the manufacturing SMEs. In some cases it was necessary to change the market segment in which the firm operated, as trade openness and MERCOSUR increased the possibilities of differentiation. In order to compete in the "new" market, these firms had to embark on an extensive innovation process: otherwise they were relegated to marginal markets or had to go out of business altogether. Martin (1993) noted that firms were failing to take full advantage of the new opportunities because they were still trying to get the most out of the old ones.

In a way, it was the greater external openness rather than MERCOSUR itself which modernized the markets for many goods: it not only brought in new competitors but also reformulated the operating conditions by acting directly on the demand profile. For the industrial SMEs, then, the competitive challenge was not limited to manufacturing their goods at prices comparable with those of imports but also involved the restructuring of their businesses by making innovations in other areas of management (such as more precisely defining their target market and forms of marketing). Some case studies reveal that many SMEs which sold almost $100 \%$ of their output to final consumers through their own outlets have begun to use wholesale intermediaries in order to multiply their points of sale. For many enterprises this strategy has meant, among other things, modifying their cost, price and markup structure; redefining production times and volumes in order to simultaneously deal with types of demand having different sales cycles, and changing their current financing scheme and debt collection system. In the light of the new market situation, many SMEs have had to choose between various options and capabilities in answering three key questions on their production strategy: i) who really are their clients, market segment and competitors?; ii) what products and services should they offer?, and iii) how should they reorganize their activities in order to meet demand efficiently?

There are two more elements which should be mentioned in this respect. First, it is obvious that the SMES in the MERCOSUR countries are not necessarily competing with those of the other member countries. On the contrary, in many industrial branches and niches the main competitors of local small and medium-sized enterprises are much bigger firms operating in the European and North American markets. Many of them have been operating in the international market for many years and have gained a stock of experience and competitive advantages that SMES -especially those of Argentina and Uruguay- do not possess. Consequently, redesigning their business has become a crucial item on the agendas of many firms in the sector.

Second, the small and medium-sized enterprises of MERCOSUR are not competing only with firms (including SMEs) from other countries. In reality, the local firms -which, as we shall see below, had been operating in great isolation and with very few linkages- are competing with "production systems" in which the firm that actually produces or markets a good bases its competitiveness on a system of production relations and institutional frameworks which significantly aid its position in the market and in the construction of systemic competitive advantages.

\section{Repositioning firms in the expanded market and beginning a process of internationalization}

In recent years, many SMEs have attempted to broaden their market horizons through the tariff advantages provided by MERCOSUR. Although there has been a big increase in the number of firms exporting on a small scale to neighbouring countries, particularly in the case of Argentina, the external linkages of small and medium-sized manufacturing firms are still at a very embryonic stage, especially because they cannot "copy" or emulate the external development model followed by the bigger firms in their countries, still less when the type of product 
and the provision of after-sales service may be decisive factors in their competitive advantages.

Gaining a suitable position in MERCOSUR is not only a key factor for a firm's growth but also a strategy that must be actively pursued in order to remain in its own domestic market. Except in Brazil, relying on the domestic market as the only consumer space may hamper the firm's development, especially when there are advantages of specialization and scale. In future years, the "MERCOSUR market" will be the main driving force and stimulus on the business scene.

The MERCOSUR SMEs have little experience in external trade operations and, with a few exceptions, have had great difficulty in incorporating this market in their strategies. Obviously, there is no "one and only" business strategy for beginning a process of internationalization; even within the borders of MERCOSUR such a strategy will depend on many different factors: type of product, market segment that the firm is aiming at, operational capacity and capacity for remote management, management style, and willingness to develop arrangements for association, among other things.

The incorporation of MERCOSUR as the prime market for a firm raises a number of issues which were not always on the previous business agenda: new clients with new and different needs; access to reliable and accurate information on clients and markets, regarding which the firm may previously have had very little knowledge; the need for a medium-term commitment to invest time, human and financial resources in entering the market; access to new financing schemes; application of a new logistical approach for supplying outside markets, etc. This more complex situation does not necessarily require sophisticated formal planning, but it does call for the effective coordination of a number of different capabilities and types of know-how, several of which directly depend on the SMEs' access to the necessary information. Others depend on the support of local institutions and the links established by the latter.

A key element in this respect is the willingness and openness of entrepreneurs to seek forms of external linkages which involve the active participation of "third" partners, in some cases intermediaries, and of representatives and consultants, and the existence of effective links with support bodies and information centres. The studies made on commercial agents and the exports of Argentine SMEs to Brazil reveal a certain paradox: on the one hand, the owners of SMES emphasize that independent control of the running of the firm is a central element in their entrepreneurial "culture" and manner of running their businesses, but on the other hand it is essential to establish direct and active links with market agents in order to secure efficient external linkages. This obliges firms to seek forms of business cooperation which represent substantial innovations in business management and, to some extent, affect this attitude of individualism.

\section{Updating of technology in order to face external competition in MERCOSUR}

When we look at the figures for MERCOSUR imports of industrial goods in recent years, the first point that strikes us is that with their industrial production in general and that of the SMEs in particular, the MERCOSUR countries -rather than competing with each other -are competing with the industrial goods of countries with a higher level of relative industrial development: a situation which involves, among other things, a technological confrontation. For example, if we analyse the main external trade items of Argentina and Brazil in the categories of mechanical goods, capital goods for industry, informatics, communications, tools and industrial equipment we see that in 1995 MERCOSUR imported goods worth some US\$ 15 billion, of which only $11.2 \%$ (US\$ 1.6 billion) came from within MERCOSUR. Some $25 \%$ of the imports came from firms in the United States, over $10 \%$ from Germany and a similar proportion from Italy, rather less than 9\% from Japan, some 5\% from South Korea, and similar amounts from Spain and France. Likewise, $90 \%$ of the imports of some fine chemicals and petrochemical products were supplied by competitors from outside MERCOSUR: mainly the United States, followed by Germany, Switzerland, Great Britain, Belgium and Japan.

In the economic and business administration literature there has been an extensive discussion on the factors determining competitive advantages. From a non-conjunctural standpoint, some authors hold that the competitive advantage of a firm is the reflection of its owners' or managers' skill in coordinating and organizing a number of key basic capabilities, some of them internal and others deriving from the production environment (Prahalad and Hamel, 1990; Dierickx and Cool, 1989). In the manufacture of their products, firms use both tradeable capabili- 
ties (the labour factor and the available infrastructure) and non-tradeable assets (their production experience). Although the availability, quality and low relative prices of the former are a necessary condition for good performance by the enterprise, they are not of themselves sufficient to ensure advantages that will be sustainable in the medium term, since they are freely accessible and potentially capable of being developed (i.e., imitable and offsetable) in any market. Dynamic competitive advantages are also based on capabilities or assets which are specific to the enterprise or the local/sectoral system and which in many cases cannot be purchased or acquired in the market (product innovation, reputation for reliability, image of high quality, etc.). In a changing economic setting which is increasingly competitive and internationally open, these assets largely determine an enterprise's competitiveness, position and performance in the market.

For many SMEs, the intention of coming closer to international standards means evaluating in what aspects of production they have the necessary minimum capabilities and qualifications, how they can concentrate their competitive advantages on their specific assets, and how they can secure the ongoing development of such capabilities. ${ }^{7}$ Surveys made among Argentine and Uruguayan SMEs indicate that in general they lack information on the latest international technological advances and also automatically equate "technological level" with the level of equipment. Very few entrepreneurs have international yardsticks to compare their firms with, and most firms depend very much on private suppliers of equipment.

When analysing the process of technological change in SMEs from outside the enterprises, there is a tendency to think in terms of a sequential model with three successive stages: i) the firm is in a more or less stable situation, but for some reason (such as shifts by competitors or clients) it decides to carry out technical or organizational changes; ii) the firm proceeds to implement the planned changes, and iii) it then returns to a stable situation. In the literature on business administration this sequence is called freeze, change and re-freeze. The process of change is treated as a discrete event or object (for example, it takes the form of the acquisition of equipment and lasts for a specific period of time).

In reality, however, the present technological modernization process is much more complex and quite different from the interpretation of the traditional model, not only because the business environment is more turbulent, volatile and rapidly changing, but also because the process of organizational and technological change has no predetermined final point and is open to the particular forms of evolution and implementation of each enterprise. In other words, several of the new needs of enterprises (such as operational flexibility) are associated with the introduction of operational techniques, tools and procedures and economic management decisions which derive from open-architecture technologies that can be adjusted and redesigned according to needs and applications. ${ }^{8}$ Organizational and technological change thus represents an ongoing process of implementation and use.

This is a key point for the organization and implementation of the technological modernization that firms must carry out and for the design of support services. Unlike the past, when the purpose and results of technological change were well-defined and delineated, and a single special measure could therefore be taken to deal with each problem ("one problem, one shot"), the present situation means formulating and developing a scheme of work adapted to the new ongoing and recurrent nature of technical change, seen as a "stable" situation in which the need may nevertheless arise for many unforeseen changes.

\footnotetext{
${ }^{7}$ One of the most serious problems faced by SMEs is the deterioration which has taken place in their capabilities and competitive advantages in recent years and the disinvestment they have suffered. Although intangible strategic assets are not depleted with use, as tangible assets are, they nevertheless need to be constantly replenished. In the terms used in business administration, these assets are eroded, lose their complementarity and become outdated. In past decades many SMEs have only covered their amortization commitments, since their strategies were guided by short-term decisions.
}

\footnotetext{
8 "Successful moves toward "the factory of the future" are not a matter of small adjustments made independently ... but rather have involved substantial and closely coordinated changes in a whole range of the firm's activities. Even hough these changes are implemented over time, perhaps beginning with "islands of automation", the full benefits are achieved only by an ultimately radical restructuring" (Milgrom and Roberts, 1990, p. 513).
} 


\section{Taking advantage of the new opportunities arising in MERCOSUR}

These opportunities derive from new investments and from the reconfiguration of "regional industrial value chains". SMEs are not "islands of production" divorced from the productive and technological dynamics of the respective production subsectors. Indeed, many SMEs do not produce final goods but instead manufacture inputs, parts or components or carry out processes for other enterprises. As is clearly shown in the economic literature, the functional production linkages (with subcontractors or component manufacturers) of the SMEs have grown in recent times, especially as a result of the processes of tertiarization and de-verticalization of the bigger industrial firms, both those engaged in terminal production and those carrying out assembly activities. All the time, more complex and advanced forms of interaction are being introduced, ranging from long-term contracts including product research and development commitments to the participation of subcontractors within the terminal plant itself, at work stations carrying out part of the final production of the good in question. There are also clear indications that the potential for the establishment of external linkages by SME subcontractors depends precisely on their production links with big national and transnational corporations.

MERCOSUR is a regional economic space which channels production investments of considerable magnitude, designed or decided in the light of internationalization and globalization. Increasing the links of local SMEs with this new wave of investments is a challenge both for entrepreneurs and for the public authorities, since it undoubtedly represents a starting point for the development of small and medium-sized enterprises in MERCOSUR. The emergence of new dynamic sectors as areas of private and international investment (telecommunications and information technology, the motor industry, equipment for privatized services, infrastructure, energy) should make it possible to set in motion a process of reconversion and growth of new enterprises forming part, from the very beginning, of an integrated economic space and an international technological environment.

\section{IV}

\section{Some features of MERCOSUR SMES which make it more difficult to modify their historical tendencies}

The challenges referred to in the foregoing pages represent sources of concern for the small and medium-sized enterprises currently operating in the market, which have their own background, history, business culture and economic and non-economic objectives and which have been developing specific features and ways of operation over many years. For many authors, these special features of the SMEs of Latin America and the Southern Cone region sum up to some extent the history of the economic policy and industrial evolution of those countries and of the business sectors involved.

The successive economic conditions and situations of competition which prevailed in the various domestic markets gave rise to certain forms of behaviour and business culture among the firms; cer- tain habits and forms of organization of labour became reflected in management methods and were central factors in defining the business strategies followed. Although the firms have been adapting their models and techniques, business culture is deeply impregnated with the specific local and national conditions. In the new economic and regulatory environment, some of these features represent elements of conflict: in some cases because they are reflected in passive entrepreneurial attitudes, and in others because they make it difficult to incorporate new technologies and forms of operation or because this would mean breaking with traditions which are deeply rooted among entrepreneurs and departing from the management structures which they themselves had been developing over time. 
As is well known, a large part of the SMEs are run on a family basis, and the figure of the owner carries great weight in them. These features have repercussions on various aspects of the economic and production activities of the firm and give such firms a special character, very different from that of other productive organizations. Indeed, as Brytting (1990) noted, SMEs are only partially a rational phenomenon, since they reflect the ways of thinking, beliefs, values, feelings and very life of the persons involved in them. The weight of the figure of the owner-entrepreneur-manager is expressed and reflected in many different ways. It even imparts a relative character to the concept of the "success" of the firm (as regards maximizing profits, for example), since this may be connected with the personal aspirations of the owner, which do not necessarily reflect a "typical" rational and optimal form of behaviour, may vary over time, and change with the development of the firm itself.

In the case of the SMEs of Argentina and Uruguay, on the operational level of management these characteristics are reflected in the following features:

\section{a) High degree of centralization of decision-making} in the firm

This gives rise to a pyramidal operating structure with few levels but severe limitations on delegation of functions and empowerment of staff ("L'entreprise, c'est moi!"). On the other hand, there are very close and personal ("face to face") relations among the various members of such firms, which generally have great motivational value. In many SMEs, however, the roles of the various staff members are indeterminate, and rather than giving rise to a system of management which is efficient, smooth-running and versatile, with strong intercommunication, this finally results in a confused system of makeshift interdependence and overlapping of duties.

\section{b) Closed structure of ownership}

Because of this characteristic, it is often very difficult to distinguish between the formal property of the firm and the personal property of the owner-manager and his family. This feature is not only clearly reflected in the overlapping of family property, the assets of the firm as such, and management tasks, but also often represents a serious barrier to the development of forms of business association or an increase in the firm's capital through the partic- ipation of outside (non-family) partners or institutional investors (such as larger firms). The family nature of the firm is often a serious impediment to the incorporation of capital from financial sources (venture capital institutions), as the owner-managers perceive this as the possible loss of their unilateral control of the business.

\section{c) Other common elements mentioned in recent studies}

Some recent studies on administrative-strategic management in SMEs (Kantis, 1996; Yoguel, 1995; Boscherini and Yoguel, 1996) highlight the following common elements:

i) SMEs generally lack formal operating procedures and in many cases they do not have written regulations on production operations, quality and other aspects. In many firms there is only a limited level of development of some business functions (such as marketing), and little use is made of management techniques and strategic information.

ii) Although a large part of their business management efforts are concentrated on short-term operational matters -which, apart from being crucial for the profitability of the firm, are the area of decision-making in which the typical owner-manager is most at ease- the "planning" horizons reflect the different styles and cognoscitive abilities of the owner-managers (construction of medium-term expectations).

iii) They operate on the basis of highly concrete projects whose sequence determines the evolution and trajectory of the firm in the medium term. This process (seen ex post) displays frequent advances and retreats and is strongly influenced by short-term factors and random personal considerations, as well as by the instability of the macroeconomic environment.

iv) Much of their strategic management is based on the intuition and personal experience of the entrepreneur and his perceptions on the market dynamics and the options open to the firm in view of its capabilities and basic competitive assets. Disparities between actual market conditions and the perceptions of the entrepreneur may go a long way towards explaining why firms of this type may adopt very different strategies although faced with similar situations.

v) They do not normally use external services or consultants, since they rely very much on their own resources (human and financial). This behaviour re- 
flects a culture and attitude which prefers (or has preferred in the past) to solve problems unaided, often spurning the benefits that a more open and collaborative attitude could bring. The entrepreneur running the firm generally takes the view that it has well-defined limits and that some of the arrangements in networks or consortia are confusing.

vi) Their main source of information consists of other individual entrepreneurs, and little use is made of the facilities provided by Chambers of Industry and the public support systems. Indeed, entrepreneurs are often simply unaware of certain support systems or have little confidence in them because they consider them far removed from the everyday problems of the SMEs (which indeed is often true).

vii) Albeit in an informal and somewhat anarchic manner, the SMEs (or rather their owner-managers) are engaged in a constant learning process of which there are few formal records. The process is based on the need to tackle and solve particular unexpected problems, and it gradually builds up the stock of intangible assets of the firm, thus largely determining its capabilities and competitive advantages in the market. ${ }^{9}$

The widely differing perceptions of the entrepreneurs about the directions, rates and magnitude of the changes faced by each SME in its particular market segment as a result of the establishment and initiation of MERCOSUR fostered and conditioned a variety of different decisions by these firms (for example, revision of their production profile and market orientation, rationalization of employment, incorporation of new products and product special-

\footnotetext{
${ }^{9}$ During the first decades of development of SMEs in the various Latin American countries (from the end of World War II to around 1970) these enterprises made technical adaptation efforts in order to reconcile local scales of production with the operational rigidity of the installed equipment and bring the different practices and standards of quality and operating efficiency in line with the demands of domestic intermediate firms or final consumers. They carried out a sustained learning process, starting from a low level, in all aspects: business management, organization of production, labour relations, etc. Taking advantage of their three main sources of knowledge (clients, importers of equipment, and the experience of the owners and their technicians themselves), the SMEs carried out an internal learning process which involved learning by doing, learning by copying and learning by using. The highly individual and in-house nature of these processes gave rise to very heterogeneous experiences which were later reflected in the very unequal histories of the firms in question (Quintar and Castaño, 1992).
}

ization, acquisition of technology and investments, development of projects on minimum quality standards, increase in imports of inputs, development of trade relations with Argentina or Brazil, sale or closure of manufacturing plants, etc.). The entrepreneurial responses of the SMEs were neither spontaneous nor all in the same direction. Although there are some common elements which predominate in many of their strategic responses (such as efforts to improve manufacturing and management productivity), the entrepreneurial trends of the last few years support the idea that, both in the formulation and the application of their microeconomic actions, the really decisive and important feature of the SMEs is their "singularity". 10

d) High degree of intra-firm vertical integration, few forms of collective action (networks and consortia), low levels of subcontracting, and excessive in-house production

There are various explanations for this excessively introverted production behaviour, ranging from the high transaction costs prevailing in highly unstable macroeconomic environments to factors originating in the firm's own conduct, such as considering that it is more profitable to produce many of the production components and carry out a large part of the production processes within the firm itself. This type of conduct led to many sub-optimal operating results and to inefficiencies in the organization of production and the handling of investments and innovations, which were further aggravated, in turn, by defensive strategies aimed at reducing costs by diversification and expansion of the range of products supplied.

\section{e) Wide variety of products and low volumes of pro- duction}

This feature is due, especially in the case of Argentina, to individual survival strategies at the enterprise level. The idea of broadening the range of

\footnotetext{
${ }^{10}$ This marked individuality of the SMEs' responses is not only connected with personal features of their owner-managers and/or very special operational factors but was also heightened by the introverted, closed and uncooperative entrepreneurial style which kept the firms in a state of marked technical "isolation" in past decades, thus preventing them from taking advantage of the possibilities of synergies and production linkages and the benefits of external economies.
} 
goods produced and often internalizing the production of parts and components is due above all to a desire to reduce costs through fuller utilization of the available physical capital (plant, equipment, human resources). These "supply-side" strategies very rarely result in effective economies of scope; on the contrary, they end up causing commercial diseconomies for firms with structural marketing difficulties and give rise to operational complications in the industrial plants themselves.

\section{f) Erratic sources of finance}

The level and profile of the investments of SMEs has depended to a large extent on their erratic sources of finance. As repeatedly noted in the specialized literature, SMEs have less access to the capital markets than big corporations. This difference is due to a very wide variety of factors, ranging from a certain degree of informality on the part of SMEs and poor accounting and project documentation to the nature and size of the guarantees demanded by finance institutions to cover the risks of such operations. SMEs mostly finance their investment processes with their own savings: that is to say, they reinvest profits or family funds. Formal long-term bank finance, which has been very scarce and expensive in many countries because of the macroeconomic situations experienced, occupies a distant second place. These enterprises tend to make more use of bank finance (loans or current account overdrafts) for their current operations, as working capital. There has been very little development in Latin America of other more complex forms of bank finance, such as venture investment funds or venture capital.

g) Markets with a restricted geographical horizon The great majority of SMEs operate in markets with a restricted geographical horizon, generally of sub-national scale. Although this situation varies from one country to another, it is particularly true in the case of Argentina and Brazil. In these countries, where there are territorially well-defined sub-markets, the presence of these enterprises in each of them does not necessarily mean that there is competition (at the national level) between them and similar firms in other regions, as such sub-markets have a low level of contacts and are not subject to arbitrage operations. Gaining access to information is not a simple matter for the SMEs, and because of the limited volumes involved there are no compensatory transactions which take advantage of the small rents available in other locations and markets. Paradoxically, there are many SMEs which have embarked on internationalization before making more decisive efforts to progress in the domestic market.

\section{h) The special forms of operation of the markets in which SMEs operate}

Since much of the output of SMEs consists of goods which are not commodities and are heterogeneous, may be technically different, and display a very wide variety of qualities and prices, the markets in which they operate work in ways which are quite special, rather obscure, and suffer from imperfections of various types which give rise to more personal and subjective attitudes on the part of consumers and entrepreneurs. Moreover, many industrial SMEs which produce final goods have their own retail marketing structure (those engaged in the production of ready-made clothing and knitwear, for example), so that they operate directly in the final consumer market, while others market their goods through independent agents, wholesalers or commercial distributors.

Many of these features have been built up over decades and are obstacles to successfully meeting the business challenges described earlier. Since a return to the old conditions in the matter of regional integration and the trade environment is highly unlikely, these SMEs must reformulate their business, seek new forms of organization, develop new capabilities and advantages, and embark on internationalization based on specialization.

In conditions of trade openness and strong competition, SMEs can only survive if they are specialized and form part of a social and economic context that favours collective growth (Bianchi, 1993). More explicitly, this means: individual productive specialization in order to attain competitive scales and levels of productivity; mutual complementarity and enhanced division of labour as an essential counterpart of specialization; collective or group efficiency as the final basis for competitiveness, and a willingness to engage in innovation and shared growth, as each firm is too small an agent in the process of internationalization to be able to eschew concerted action in conjunction with other firms and institutions.

Obviously, the achievement of some of these objectives is not a simple task and cannot be carried out on a purely individual or unilateral basis. On the one 
hand, this is because the design and implementation of some of these actions and activities require services exogenous to the firm (information, advisory assistance, training, finance), but also, and even more importantly, because these changes will not be able to secure higher yields unless they are conceived and linked together as an associative competitive strategy in an atmosphere of inter-firm cooperation (Bianchi, 1993; Hatch, 1991).

Individual actions by firms can of course improve their profitability and competitiveness, but their position in the production structure and the market will be much more solidly based if they are integrated into and share an industrial and entrepre- neurial system which develops systemic competitive advantages of a collective nature. Otherwise, the possibilities of reconstructing and expanding basic capabilities will be severely restricted by the limits of the firm itself, from those of a purely financial nature to those connected with technological innovation or negotiations on technical regulations and standards. In this sense, possibly one of the most "costly" features of SMEs in the light of the new situation and the construction of the advantages now required for successful operation is connected with the isolation of these firms from other companies and from their technico-productive and institutional support environment.

\section{V}

\section{Final remarks: technical support requirements}

It is generally acknowledged, as noted by Keesing and Singer (1991), that adequate technical services are not enough to make up for unsatisfactory policies, so that they are a complement to but not a substitute for suitable policies, resources and infrastructures. The SMEs of MERCOSUR are now facing a situation of industrial competition and technological change very different from that of past decades, and they need a system of support which forms an integral part of a strategy and policy for the sector.

Openness, integration and competition are the salient features of the environment in which an industrial policy strategy must be formulated for SMEs, and if competitiveness is seen as the central element in this it is necessary to foment the formation of a private and public system of technical and financial support to cooperate with firms in the ongoing development of their capabilities and competitive advantages. Although these firms do need measures to take care of their short-term requirements, their needs are not merely the sum of isolated problems. In many cases the most pressing problems are not those which are most crucial or really important. Moreover, the lack of some factors or capabilities in a firm cannot be solved automatically by supplying them from outside, as though the firm were a passive recipient to be "filled up" with a solution; in reality, such shortcomings can represent development potential and areas of learning for the firms if they are perceived as opportunities for creating new capabilities and skills.

This means that policy proposals and instruments must be very closely linked up with the requirements of the firms and their changing needs to improve their competitiveness.

From a more functional standpoint, the needs of SMEs could be grouped in four main areas: i) improvement of the regulatory and operational framework of their business; ii) access to specific information and advisory assistance in interpreting it, including here everything from trade information and details of technical standards to technological consultancy services; iii) the development of in-house capabilities (human resources, especially in the areas of business skills and management) and easier access to a technical services infrastructure, and iv) finance on equal real conditions to those enjoyed by bigger firms, which in some cases would mean the implementation of new financial instruments and products.

The strategic challenge when designing industrial policies for SMEs is to create or promote the establishment of an environment favourable to reconversion. Public policies cannot define or carry 
out business reconversion in a voluntaristic and all-powerful manner, as it was once believed in some circles. Instead, public policies must stimulate and create the best conditions for causing such reconversion to take place efficiently, giving priority to the construction of collective synergies that will be sustainable over time. Otherwise, public action would be open to criticism for being passive (for not doing anything) or even retrogressive (for favouring actions going in the opposite direction).

The hub of the reconversion process consists of the enterprises and the industrial production systems (or subsystems): that is to say, the value chain. This process is inherent in the firm itself, and is therefore largely an endogenous process which must be conceived in the light of the culture and objectives of the firm. It goes without saying, then, that the main actors and clients of the corresponding policies are the SMEs, so that their active participation as requestors and users is essential.

In order to create an environment of change we must therefore discard the idea of a closed system, designed a priori from above, which is assumed to know what entrepreneurs' needs are in advance and also possesses the necessary solutions. On the contrary, the strategy for working with the SMEs should be aimed at generating an open, self-regulating and self-sustainable multi-institutional space which allows the users (the SMEs) to obtain what they need for reconversion -technical know-how, training, advisory assistance, information, finance, transfer of technology, business services or qualified suppliersand allows the suppliers to provide products and services for the reconversion process with similarly entrepreneurial criteria. The role of the national political authorities will thus consist of formulating an industrial strategy, designing and implementing global policies and also measures for more decentralized application, overcoming the existing impediments to making the integration programme more effective, improving the regulatory framework and the business environment, and taking care of external trade negotiations and following-up and evaluating the firms' performance.
Finally, there are some lessons that can be learned from the relations between SMEs and the technical support system. The first of these is that SMEs have difficulty in interacting and establishing cooperative links. For many of them, the first step in the innovation process should involve modifying the practices and behaviour of their owners. Second, their main production linkages (apart from the fact that an SME may operate in relative isolation) are with private economic agents (suppliers, clients, subcontractors, competitors, equipment firms, banks, etc.), and these relations represent their main sources and channels of technical information, implicit or formal advisory assistance, and technological demands, so that every public action or initiative must be established in this technical, productive and commercial area of relations. Third, the services offered cannot be expected to be successful unless they are in line with the requirements, capabilities and special features of the firms and their managers, and these are of course different from those of big firms as well as being very heterogeneous among the SMEs themselves.

The process of changing the firms must be practicable in the short term. For this reason, it is essential to define the policies and activities corresponding to the transitional stage and the following phase very clearly. It is necessary to make a clear distinction between actions and initiatives designed to smooth the transition from one organizational model to another, on the one hand, and the policies to be applied when a number of aspects of the functioning of the firms and the industrial system have already been changed. It must be borne in mind, for example, that the information requirements are different in the two situations; it is no use meeting the needs of the second phase if crucial aspects of the first stage have still not been solved. In some countries, many of the shortcomings in their technical support systems are due precisely to the confusion of these two stages, "during" and "after", which leads to methodological errors in assigning priorities to objectives and activities.

(Original: Spanish) 


\section{Bibliography}

Bianchi, P. (1993): Industrial districts and industrial policy, Journal of Industry Policy, vol. 1, No. 1.

Boscherini, F. and G. Yoguel (1996): El fortalecimiento de la capacidad innovativa: el caso de las Pymes exportadoras argentinas, Documento de Trabajo No. 71, Buenos Aires, ECLAC Office in Buenos Aires.

Brytting, T. (1990): Spontaneity and systematic planning in small firms -A grounded theory approach, International Small Business Journal, vol. 9, No.1, Macclesfield, Cheshire, U.K., Woodcock Publications Ltd.

Dierickx, I. and K. Cool (1989): Asset stock accumulation and sustentability of competitive advantage, Management Science, vol. 35, No. 12.

Ferraro, C. (1994): Ruedas de negocios y cooperación empresaria en el MERCOSUR: análisis y seguimiento de las Ruedas de Negocios organizadas por el SEBRAE-Rio de Janeiro en Buenos Aires, Documento de Trabajo No. 56, Buenos Aires, ECLAC Office in Buenos Aires.

Gatto, F. and C. Ferraro (1993): Las Pymes en el MERCOSUR: definiciones y primeras estimaciones, Documento de Trabajo No. 37, Buenos Aires, ECLAC Office in Buenos Aires.

-(1997): Consecuencias iniciales de los comportamientos Pymes en el nuevo escenario de negocios en Argentina, Documento de Trabajo No. 79, Buenos Aires, ECLAC Office in Buenos Aires.

Hatch, R. (1991): The power of manufacturing networks, Entrepreneurial Economy Review/Transatlantic Perspectives, No. 22.

IDB (Inter-American Development Bank) (1995): Estrategia de desarrollo empresarial para la Argentina. Informe final, Buenos Aires, mimeo.

INDEC (National Institute of Statistics and Censuses) (1997): Censo Nacional Económico, Buenos Aires.

Kantis, H. (1996): Inercia e innovación en las conductas estratégicas de las Pymes argentinas: elementos conceptuales y evidencias empíricas, Documento de Trabajo No. 73, Buenos Aires, ECLAC Office in Buenos Aires.

Keesing, D. and A. Singer (1991): Assisting manufactured exports through services: New methods and improved policies, The Role of Support Services in Expanding Manufactured Exports in Developing Countries, Washington, D.C., World Bank, Economic Development Institute (EDI).

Martin, R. (1993): Changing the mind of the corporation, Harvard Business Review, Boulder, Colorado, Harvard University, November-December.

Milgrom, P. and J. Roberts (1990): The economics of modern manufacturing: technology, strategy and organization, American Economic Review, vol. 80, No. 3.

OECD (Organization for Economic Cooperation and Development) (1997): Globalization and Small and Medium Enterprises (SMEs), vol. 1, Paris.

Orlikowski, W. and D. Hofman (1997): An improvisional model for change management, Sloan Management Review, Cambridge, Massachusetts, The MIT Press, Winter.

Prahalad, C. and G. Hamel (1990): The core competence of the corporation, Harvard Business Review, May-June.

Quintar, A. and A. Castaño (1992): Historia de las pequeñas y medianas empresas metalmecánicas de Rosario, Buenos Aires, Programa CFI-CEPAL, mimeo.

Storey, D. (1987): Size and performance: Size, profit and growth in small and large companies, in D. Storey and others, The Performance of Small Firms, Routledge, London.

Walsh, J. and J. White (1981): A small business is not a little big business, Harvard Business Review, Boulder, Colorado, Harvard University, July-August.

Yoguel, G. (1995): Reestructuración económica, integración y Pymes: el caso de Brasil y Argentina, in J. Katz (ed.), Estabilización macroeconómica, reforma estructural y comportamiento industrial; estructura y funcionamiento del sector manufacturero latinoamericano en los años 90, Buenos Aires, Alianza Editorial.

Yoguel, G. and others (1997): Programa de mejoramiento de las capacidades tecnológicas de las Pymes, San Miguel, provincia de Buenos Aires, Universidad Nacional de General Sarmiento, Instituto de Industrias. 